\title{
CURSO DE PEDAGOGIA: EPISTEMOLOGIA E CURRÍCULO
}

\section{PEDAGOGY COURSE: EPISTEMOLOGY AND CURRICULUM}

\author{
Marli de Fátima Rodrigues*
}

\begin{abstract}
RESUMO
O presente artigo apresenta uma reflexão acerca da necessidade de se avançar na definição do campo epistemológico da pedagogia. Esta análise de natureza bibliográfica e documental tem como objetivo demonstrar que a falta de clareza ainda presente ao diferenciar concepção de pedagogia e estrutura de curso tem se configurado como um grande obstáculo para o avanço dessas discussões. Destaca-se que ao se avançar na definição do campo epistemológico da pedagogia define-se com mais clareza sua estrutura curricular. Reafirma-se a hipótese de que a identidade do curso de pedagogia está estreitamente ligada à sua definição enquanto campo de conhecimento e de investigação.
\end{abstract}

Palavras-chave. Pedagogia. Epistemologia. Currículo.

\begin{abstract}
This article presents reflections about the need to develop better definitions of the epistemological field of pedagogy. The analysis is based on a literature review and on document research and aims to demonstrate that the lack of a clear understanding of the differentiation between the conception of pedagogy and the structure of Pedagogy courses has been an obstacle for the advancements of such discussions. The article highlights that better understandings of the epistemological field of Pedagogy reflects in a clear structure of the course. The hypothesis that the identity of the Pedagogy Course is closely linked to its definition as an area of knowledge and investigation is also reaffirmed in the article.
\end{abstract}

Keywords. Pedagogy. Epistemology. Curriculum

\section{Introduçao}

A polêmica em torno do curso de pedagogia não é nova, muitos autores já trataram desta questão ${ }^{1}$, sendo inclusive proposto, em alguns momentos, a sua extinção. As maiores discussões têm emergido juntamente com as propostas de regulamentação e, apesar da grande produção de dissertações, teses e publicações, questões recorrentes como as que tratam do objeto de estudo e da identidade do curso de pedagogia, de forma explicita e latente, percorrem todo o histórico desse curso. O debate foi reanimado com a promulgação da LDBEN 9.394/1996 e

\footnotetext{
" Graduada em pedagogia (UEPG, 1995), mestra em educação (UFF, 1999) e doutorado em educação (UFPR, 2005). Professora concursada na área de política educacional da UEPG.

${ }^{1}$ Para citar alguns autores: com respeito à identidade do curso de pedagogia, Bissoli da Silva (1999); suas funções, Brzrezinski (1996), Bissoli da Silva (1999); sua natureza e especificidade, Pimenta (1998, 2000), Libâneo (1998, 2000). 
com as propostas de mudanças nas políticas para a formação de professores e de pedagogos ${ }^{2}$.

Retomo inicialmente parte do discurso proferido por Moacir Gadotti em março de $1978^{3}$, a respeito do curso de pedagogia:

Vamos notar que é um dos cursos que menos tem evoluído, mantendo-se até mais estático do que os demais. O currículo do curso de pedagogia é o mesmo desde os primórdios do nosso ensino superior; quase nada se modificou. Até os atuais cursos de pós-graduação em educação repetem as disciplinas que são dadas nas escolas normais desde sua introdução no Brasil. Diante dessa resistência à inovação, formulo duas hipóteses: ou a educação é um fenômeno simples, cuja compreensão, no máximo, poderia exigir alguns aprofundamentos circulares em torno do mesmo dado inicial, ou ela é um fenômeno complexo. No segundo caso, então, os pedagogos mantendo-se sempre fiéis à mesma tradição, estariam, no mínimo, enganando-se com relação a seu "objeto" de estudo e de ação. (GADOTTI, 2001, p.85).

À época, esse autor destacava que o curso de pedagogia oscilava entre pretensões fundamentadas em um humanismo idealista e um humanismo tecnológico que reforçavam uma dimensão conservadora dos processos pedagógicos, reproduzindo as relações sociais de dominação e colaborando para se perpetuar da situação vigente. Embora tenham se passado mais de 30 anos, essa afirmação incomoda sobremaneira, especialmente pelo fato de pouca coisa ter mudado em relação ao curso de pedagogia. Ouso inclusive elencar alguns aspectos que mostram a atualidade dessa afirmação.

Primeiro: a afirmação foi feita em um momento de grandes discussões a respeito do curso, bastante similar às discussões realizadas após a aprovação da Lei 9.394/1996. A polêmica sobre o destino do curso de pedagogia reaparece fortemente, uma vez que a nova legislação propôs a criação dos institutos superiores de educação e do curso normal superior e, mais recentemente, com os embates e as posições

\footnotetext{
${ }^{2}$ Segundo Pimenta (1998, p. 9), as discussões de redefinição desse curso são iniciadas no final da década de 1970, especialmente por meio de três teses produzidas na PUC-SP, por Selma Garrido Pimenta (1985), Celestino Silva Júnior (1985) e Vitor Henrique Paro (1988). Nesse momento, questionavase a identidade do curso de pedagogia e do profissional pedagogo.

${ }^{3}$ Notas de uma palestra proferida pelo professor Moacir Gadotti aos professores do curso de pedagogia da PUC-SP, em março de 1978, e publicada no livro Educação e poder: Introdução à pedagogia do conflito (2001).
}

divergentes a respeito de percursos curriculares para a formação do pedagogo, animados pela definição de suas Diretrizes Curriculares Nacionais. Tais debates fundamentaram-se em uma polarização entre duas posições antagônicas: ou a defesa de um percurso curricular definido pela docência como base de formação, ou a defesa de um currículo centrado nas ciências da educação, com ênfase nas teorias do conhecimento ${ }^{4}$. Também têm sido motivo de polêmica as contradições entre o texto da Lei de Diretrizes e Bases da Educação Nacional (Lei 9.394/1996), no seu artigo 64, o texto aprovado para as Diretrizes Curriculares Nacionais para a Formação de Professores para a Educação Básica, em Nível Superior, Curso de Licenciatura, Graduação Plena e o texto que estabelece as Diretrizes Curriculares Nacionais para o Curso de Pedagogia 5 .

Segundo: a afirmação e a argumentação feita por Gadotti mostram que os processos de formação de professores e de pedagogos estavam, naquela época, fundamentados em uma concepção de sistema educacional que articulava formação e mercado propondo um tipo de educação utilitária e eficaz para o mercado, visando a atender às exigências expressas na Lei 5.692, de 1971. Processos esses que se repetem em decorrência das reformas educacionais que acompanharam a Lei 9.394, de 1996, e suas regulamentações. É um a tendência que (re)aparece fortemente e coloca a educação sob a determinação das condições de funcionamento do mercado capitalista, denominada por Saviani (2002) de concepção produtivista de educação. A pedagogia tecnicista, sob inspiração do taylorismo-fordismo, assim como a denominada pedagogia das competências, sob a inspiração do toyotismo, com suas especificidades, fundamentam-se nessa visão produtivista, objetivada na "teoria do capital humano", na qual "prevalece a busca pela produtividade guiada pelo princípio de racionalidade, que se traduz no empenho em se atingir o máximo de resultados com o mínimo de dispêndio" (SAVIANI, 2002, p. 23).

Terceiro: neste caso, assim como nos dois anteriores, podemos identificar similaridades. A afirmação de Gadotti parte da constatação de que as reformas educacionais da década de 1970 buscavam adequar a formação de professores às necessidades

\footnotetext{
${ }^{4}$ V. Rodrigues (2005).

5 V. Rodrigues; Kuenzer (2007a).
} 
da acumulação de capital, características presentes hoje no conjunto de reformas educacionais brasileiras, que, de acordo com Kuenzer,

[...] inclui o novo modelo de formação de professores, respondendo às novas demandas do mundo do trabalho, do ponto de vista da acumulação flexível, em conformidade com as políticas das agências financeiras internacionais para os países pobres, assumidas integralmente pelo governo brasileiro. (KUENZER, 1999, p. 76).

Além das questões elencadas, outra particularmente me chamou a atenção nessa citação: ao apresentar sua segunda tese diante da resistência às mudanças e inovações nos currículos do curso de pedagogia, Moacir Gadotti afirma que, se a educação é um fenômeno complexo, os pedagogos estariam "enganando-se com relação a seu 'objeto' de estudo e de ação". Diante da afirmação, pergunto: os pedagogos enganam-se ou desconhecem qual é o seu objeto de estudo e de ação? Os problemas levantados por Gadotti a respeito da organização curricular do curso de pedagogia não seriam decorrentes da falta de identidade da pedagogia enquanto campo de conhecimento?

Impressiona também que, em 1978, Moacir Gadotti já destacava a omissão e a passividade dos educadores diante das reformas educacionais que os colocavam frente "ao esvaziamento do próprio curso e, provavelmente, a sua extinção, após ter sido estrangulado pela lei" (GADOTTI, 2001, p. 86) fato este que aparece marcadamente nos profissionais pedagogos, pois evitam discutir e enfrentar um problema que considero essencial para a definição do papel e dos desafios desses profissionais no contexto atual, qual seja, a natureza e a questão da identidade epistemológica da pedagogia.

Afinal, com tantas reformas e regulamentações, Gadotti teria razão ao afirmar que o currículo do curso de pedagogia é o mesmo desde os primórdios? De fato, as orientações curriculares para o curso têm mudado lentamente?

Por muito tempo, reproduziu-se o modelo surgido nos anos 1930. Esse modelo ficou conhecido como "Esquema $3+1$ ": aos três anos de bacharelado se acrescentava um ano de estudos didáticos para obtenção do diploma de licenciado, ou seja, à formação técnica complementava uma formação pedagógica.
Mesmo após 1962, apesar de ser instituído o princípio da concomitância, a formação do bacharel e do licenciado no curso de pedagogia é mantida, esse princípio de concomitância "não passou de um artificial paralelismo de conteúdo e método" (BRZEZINSKI, 1996, p. 57). O Conselho Federal de Educação fixou os mínimos de conteúdo e duração a serem observados na organização do curso de pedagogia. Apesar do otimismo do legislador à época, Valnir Chagas, o qual afirmava "que esta mudança representava um avanço inegável e uma revisão do esquema surgido nos anos 30" (CHAGAS, 1980, p. 333), a formação dicotomizada permanece. As disciplinas ditas de fundamentação teórica precedem o contato com a prática e a aplicação do conhecimento científico.

As habilitações foram criadas no atendimento ao artigo 30 da Lei 5.540/1968. Depois disso, o Conselho Federal de Educação propôs em parecer a formação "do especialista no professor", não admitindo candidatos sem formação de magistério. Este novo parecer institui o formato dos cursos de pedagogia com um núcleo comum de conhecimentos pedagógicos constituídos por matérias básicas à formação de qualquer profissional da área, e uma parte diversificada responsável pela formação dos especialistas, correspondendo às especialidades previstas no artigo citado acima. Foi abolida a distinção entre bacharel e licenciado para o curso de pedagogia e foi instituída a didática como matéria obrigatória do curso. Apesar de não ter sido criada uma habilitação própria, a pedagogia também passou a assumir a formação de professores para o magistério primário.

$\mathrm{Na}$ época, o licenciado em pedagogia adquiriu como "subproduto de seu curso, o direito de ser professor primário" sem uma habilitação específica para esta formação, sob o argumento de "quem pode o mais pode o menos", ou seja, "quem prepara o professor primário tem condições de ser também professor primário", argumento utilizado na época por Valnir Chagas (BRZEZINSKI, 1996, p. 75).

A respeito desta proposta, concordo com Silva: "a estrutura curricular proposta em 1969 carece de consistência do ponto de vista epistemológico e traduz uma proposta ambivalente de formação do pedagogo" (SILVA, 1999, p. 55). A autora mostra a inviabilidade dessa proposta, que fragmentava ainda mais o curso de pedagogia. 
O conselheiro Chagas, ao fazer referência ao curso de formação de professores, destaca:

Em todos os casos, a educação será encarada como um misto de arte, técnica e ciência que, de forma direta ou indireta, utiliza e integra praticamente todos os conhecimentos, projetando-se na ideia de uma educação brasileira como objetivo e condição de eficácia, o que vale dizer, como referência para avaliar as soluções próprias e adaptar as de outras procedências cuja adoção se aconselhe. (CHAGAS, 1976, p. 76)

Percebe-se que nas palavras de Chagas é negado à educação seu status epistemológico, ela não apresenta nenhuma especificidade porque "utiliza e integra praticamente todos os conhecimentos". Ao mesmo tempo, atribui-se aos cursos de formação de professores uma dimensão flexível e prática para o atendimento de resultados que deles se espera. Por consequência, o modelo de curso de pedagogia estabelecido nas três regulamentações evidenciadas reflete essa concepção.

Outras regulamentações, com o objetivo de reestruturar os cursos superiores de formação do magistério no Brasil, foram propostas por meio das indicações do Conselho Federal 67/1975, 68/1975, 70/1976 e 71/1976. Este conjunto de indicações que se referem à formação de recursos humanos para a área da educação previa, entre outras coisas, a formação do professor primário para o nível superior em uma licenciatura a ser criada, e não mais em nível de 2. ${ }^{\circ}$ grau. Dessa forma, seria excluído do curso de pedagogia o magistério pedagógico de $2 .^{\circ}$ grau. Em relação aos especialistas, previa-se que esta formação seria acrescentada aos cursos de licenciatura e, havendo condições, explicita a Indicação 70/1976, esta formação deveria ser feita em cursos de mestrado e doutorado - portanto, na pós-graduação.

Essas indicações, apesar de não homologadas pelo então ministro da Educação, levantaram discordâncias e insatisfações por parte das universidades, de associações de educadores e estudantes universitários, que passaram a se organizar para participar da definição da reformulação do curso de pedago-

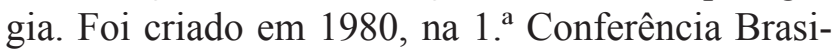
leira de Educação, realizada na PUC de São Paulo, o Comitê Nacional Pró-formação do Educador, sediado inicialmente em Goiânia, que "pela abrangência de sua ação, passou a ser um dos principais atores no cenário das disputas travadas em função do controle do processo de reformulação dos cursos de formação de educadores" (SILVA, 1999, p. 75). Os debates e a mobilização feita por educadores nesse período desencadearam a realização, em 1983, do $1 .^{\circ}$ Encontro Nacional sobre Reformulação dos Cursos de Preparação de Recursos Humanos para a Educação ${ }^{6}$, realizado em Belo Horizonte, que deu origem à Comissão Nacional de Reformulação dos Cursos de Formação dos Educadores (Conarcfe), em 1990 transformada na Associação Nacional pela Formação dos Profissionais da Educação (Anfope).

Desta vez, a discussão se polariza entre a defesa da manutenção das habilitações e a sua suspensão, por estar reproduzindo no âmbito das escolas e dos sistemas a divisão social do trabalho. Nesta linha, destaca-se o artigo intitulado "A questão política do trabalho pedagógico", publicado por Ildeu Moreira Coelho (1982) ${ }^{7}$ e resultante de uma das conferências realizadas por ocasião do $3 .^{\circ}$ Encontro Nacional de Supervisores da Educação, realizado em Goiânia, em $1980^{\circ}$. Nesse artigo, Coelho critica a fragmentação do trabalho, a atual divisão do trabalho escolar e as tentativas de redução do docente a um simples professor, colocando-se radicalmente contra as habilitações. Sua tese é de que os educadores não percebem a dimensão política da educação, concebendo-a como praticamente neutra, desligada das relações de poder e da dominação de classe. Os interesses se voltam então para os métodos de ensino, a tecnologia da educação, os instrumentos de avaliação, a adequação curricular, o conhecimento das etapas de desenvolvimento mental da criança e do adolescente. Destaca o autor que "o modo como processo a aprendizagem é tido como condição pri-

\footnotetext{
${ }^{6}$ Este encontro originou o texto que ficou conhecido como Documento de Belo Horizonte, no qual foram estabelecidos os princípios gerais que alicerçam até hoje a Anfope - entre eles, a necessidade de uma base comum nacional de conhecimento fundamental na formação dos professores; a docência como a base de identidade profissional de todo educador; a indissociabilidade entre a teoria e a prática.

${ }^{7}$ O professor Ildeu Moreira Coelho foi o primeiro presidente do Comitê Nacional Pró-formação do Educador e era, na época, presidente do Colegiado de Curso de Ciências Pedagógicas da Faculdade de Educação, da Universidade Federal de Goiás.

${ }^{8}$ Brzezinski (1996) destaca outro artigo, escrito por Miguel Arroyo, intitulado "Subsídios para uma práxis educativa da supervisão educacional", apresentado nesse mesmo evento, no qual o autor destaca o caráter técnico que assume a função supervisora no âmbito da escola, comprovado empiricamente por um grupo de pesquisadores coordenados por Arroyo. Da conclusão da pesquisa aparece como alternativa a negação da prática do supervisor especialista e a supervisão técnica, propondo a supervisão como processo educativo e o supervisor-educador.
} 
meira e imprescindível da eficácia da prática educativa" (COELHO, 1982, p. 32).

Coelho defende que essa maneira de se conceber e fazer educação reduz os graves e complexos problemas que se manifestam em nível educacional à condição de problemas meramente técnicos, "cabendo aos chamados especialistas em educação equacioná-los e apresentarem a melhor maneira de solucioná-los" (COELHO, 1982, p. 32). Em decorrência disso, o autor acredita que há uma degradação e uma proletarização crescente da força de trabalho considerada não especializada, desqualificada e semiqualificada. Sua proposta, portanto, é de extinção das habilitações, por acreditar que "a estrutura da maior parte de nossas escolas dispensa, na prática, o trabalho do supervisor, como dos outros 'técnicos' oriundos das famosas habilitações" (COELHO, 1982, p. 49).

Tal polarização se explicita também dentro do Movimento de Reformulação do Curso de Pedagogia. A manutenção das habilitações era defendida pelo grupo que representava especialmente as associações de classe, "que de modo corporativo defendiam, como fim último, a existência de sua profissão" (BRZEZINSKI, 1996, p. 157).

Outro movimento que postulava a eliminação das habilitações "era composto por um grupo de pesquisadores que entendiam ser elas apenas instrumentos utilizados para sedimentar a fragmentação do saber e do poder tanto nas escolas de formação de profissionais da educação quanto na escola de $1 .^{\circ}$ e 2. graus" (BRZEZINSKI, 1996, p. 157).

No entanto, Brzezinski (1996) afirma que, entre os grupos, havia um consenso: a docência era prioritária e base da identidade da formação do pedagogo. Tal contradição foi superada à medida que se desenvolviam os estudos sobre a base comum nacional e reafirmava-se a especificidade de cada área do saber, completa a autora.

A ideia de base comum nacional como concepção básica, defendida inicialmente como princípio e depois como diretriz, foi adotada pela Comissão Nacional de Reformulação dos Cursos de Formação do Educador, que foi instalada em substituição ao Comitê Nacional Pró-formação do Educador e mantida, a partir de 1990, pela criação da Associação Nacional pela Formação dos Profissionais da Educação (Anfope).
$\mathrm{Na}$ tentativa de encontrar respostas à questão da identidade do curso de pedagogia, a Anfope esclarece a função e define eixos para a organização curricular do curso. Todavia, como assinala Silva, no interior do próprio movimento tem-se consciência "de que essa questão encontra-se vinculada a uma outra mais profunda e complexa: a questão da identidade da própria pedagogia enquanto campo de conhecimento e de investigação" (SILVA, 1999, p. 95). Embora já tivesse se evidenciado que a questão da identidade do curso de pedagogia estaria estreitamente ligada à sua definição enquanto campo de conhecimento e de investigação, essa questão não foi suficientemente enfrentada pela Anfope.

Analisando os documentos produzidos pela Associação Nacional pela Formação dos Profissionais da Educação, conclui-se que há consenso para o movimento de que o curso de pedagogia se edifique a partir da centralidade na docência, constituindo-se a base da identidade profissional do pedagogo. Das constatações feitas, no entanto, uma questão não parece suficientemente esclarecida: qual é a concepção epistemológica no campo da pedagogia que fundamenta as discussões desse movimento?

\section{Redução do Campo Epistemológico da Pedagogia}

Como insistentemente destacam alguns autores (LIBÂNEO, 1998, 2000, 2002; PIMENTA, 1998, 2002; LIBÂNEO; PIMENTA, 2002; FRANCO, 2003), houve uma descaracterização da pedagogia como área específica de conhecimento e como campo de exercício profissional, especialmente na década de 1980 .

A identificação do curso com a formação de professores, como uma licenciatura, tem-se caracterizado como o principal aspecto responsável pela redução do campo epistemológico da pedagogia. Libâneo e Pimenta (2002) esclarecem que essa concepção foi adotada em razão de circunstâncias peculiares da história da educação do nosso país, apontadas anteriormente, como resposta às críticas da divisão do trabalho na escola com base no entendimento de que o Parecer 252/1969, ao instituir as habilitações, estaria reproduzindo a ideologia implícita na reforma universitária de 1968, segundo o modelo da administração capitalista, levando à fragmentação da prática pedagógica. 
A docência como base de formação do pedagogo, defendida pela Anfope, foi adotada por muitas faculdades de educação que em meados dos anos 1980 reformularam seus cursos de pedagogia e estruturaram seus currículos investindo na formação de professores para as séries iniciais do ensino fundamental e do curso de magistério, retirando as habilitações convencionais, de modo que algumas disciplinas foram retiradas do currículo ou esvaziadas. Para atender à docência, essas faculdades desconsideraram o núcleo científico do curso, que deveria ser em torno dos estudos especificamente pedagógicos. Essa visão, defende Libâneo (1998), tem colaborado para uma grande dispersão na investigação da temática educacional, assim como para inúmeros reducionismos. Segundo ele,

[...] o esfacelamento dos estudos no âmbito da ciência pedagógica com a consequente subjunção do especialista no docente, e a improcedente identificação dos estudos pedagógicos a uma licenciatura, talvez sejam dois dos mais expressivos equívocos teóricos e operacionais da legislação e do próprio movimento da reformulação dos cursos de formação do educador, no que se refere à formação do pedagogo. (LIBÂNEO, 1998, p. 115).

No que diz respeito à Anfope, Libâneo afirma existir um paradoxo nos documentos produzidos por essa instância: ao mesmo tempo em que insistem em uma formação ampliada do educador e na sua dimensão política, reduzem a atuação do educador à docência. Ele salienta:

Os documentos divulgados em seus encontros são genéricos, meras declarações de intenções com pouca bagagem teórica e operacional para atingir objetivos mais concretos: mudar o sistema de formação, intervir nos currículos, nas práticas de formação profissional, na explicitação do campo de trabalho profissional do educador. (LIBÂNEO, 2000, p. 105).

Para o autor, a Anfope reforça a concepção de curso adotada desde a primeira regulamentação, em 1939, ao não diferenciar a formação do professor e do especialista e ao reafirmar que o curso de pedagogia é uma licenciatura, contribuindo, dessa forma, para descarcterizar a formação do pedagogo stricto sensu.

Libâneo e Pimenta defendem que a base comum de formação do educador deve ser expressa em um corpo de conhecimentos ligados à pedagogia e não à docência", "uma vez que a natureza e os conteúdos da educação nos remetem primeiro a conhecimentos pedagógicos e só depois ao ensino enquanto modalidade peculiar de prática educativa" (LIBÂNEO; PIMENTA, 2002), constituindo-se, então, a base da identidade profissional do educador por meio da ação pedagógica, não da ação docente.

Libâneo aponta para uma formação diferenciada do pedagogo especialista e do pedagogo escolar, dada a diversidade de práticas educativas na sociedade, níveis de atuação e a realidade em que atuarão. No entanto, acredita que a formação de profissionais da educação não diretamente docentes é uma necessidade e que "um sistema de formação não pode ignorar" (LIBÂNEO, 1998).

Em síntese, contrários à tese que reduz o trabalho pedagógico e, consequentemente, a formação do pedagogo com base na docência, tendo em vista a descaracterização da pedagogia como campo teórico-investigativo e a sua identificação com uma licenciatura, Libâneo e Pimenta defendem uma concepção de educador em que a base de sua identidade profissional seja a teoria e a prática em torno dos saberes pedagógicos, sob o argumento de que não há identidade conceitual entre a pedagogia e a formação de professores. Concluem que, ao contrário do que se pretendia com o movimento de reformulação dos cursos, o revigoramento do sistema de formação de professores promoveu o seu enfraquecimento ao subsumir o campo pedagógico à docência, pois, além de restringir o campo de exercício profissional, esvaziou a reflexão teórica e epistemológica do profissional do campo da educação. Assim coloca Libâneo:

Com efeito, a negação da existência de conhecimentos teóricos e práticos próprios da ciência pedagógica (em conexão com as demais ciências da educação) e a recusa de admitir-se um campo de atuação profissional mais amplo ao pedagogo, abriram flancos a toda sorte de reducionismos, à intransigência e intelorância das posições estabelecidas nos campos do conhecimento, resul-

\footnotetext{
${ }^{9}$ Foi no $6 .^{\circ}$ Encontro Nacional da Anfope, realizado em julho de 1992, em Belo Horizonte, que José Carlos Libâneo teria defendido pela primeira vez que as faculdades de educação deveriam oferecer dois cursos distintos: o de pedagogia e o de licenciatura para a formação de professores para todo o ensino fundamental e médio, podendo receber a denominação de centro ou instituto de formação de professores. (LIBÂNEO, 1998).
} 
tando no empobrecimento da investigação pedagógica específica, no vazio teórico na formação profissional, na desvalorização da formação pedagógica-didática dos licenciados. (LIBÂNEO, 1998. p. 131).

O mais importante para esta análise é que o citado autor enfatiza que o pedagogo (escolar ou não) seria um profissional especializado em estudos e ações relacionadas à área da ciência pedagógica, destacando uma grande preocupação com um núcleo científico da pedagogia que deveria ser apresentado em torno dos estudos especificamente pedagógicos.

\section{O Problema para uma Definição da Peda- gogia como Campo de Conhecimento}

A preocupação com a base epistemológica da pedagogia surge nos anos de 1980 e alguns estudiosos despontam na década de 1990, assumindo como tarefa o compromisso intelectual de aprofundar essa temática (LIBÂNEO, 1998, 2000, 2002; PIMENTA, 1998, 2001, 2002; BISSOLI, 1999; BRZEZINSKI, 1996; FRANCO, 2003). Todavia, a falta de clareza ainda presente ao diferenciar concepção de pedagogia e concepção de curso de pedagogia tem sido, a meu ver, o grande obstáculo para o avanço dessas discussões. Há necessidade, portanto, de uma reflexão crítica sobre uma concepção de pedagogia que expresse seu estatuto teórico, sua base epistemológica, definindo-a como campo de conhecimento.

Pimenta (1998, 2001, 2002), apoiada em diferentes autores ${ }^{10}$, defende a necessidade de a pedagogia postular sua especificidade epistemológica "de modo a não se conformar com uma mera posição de campo aplicado de outras ciências, que também

\footnotetext{
${ }^{10}$ Dentre os autores referenciados por estão SCHMIED-KOWARCZIK, W. Pedagogia dialética: De Aristóteles a Paulo Freire. São Paulo, Brasiliense, 1983; COELHO; SILVA, J. P. C. Das ciências com implicações na educação à ciência específica da educação. Revista Portuguesa de Pedagogia, Coimbra, ano 35, n. 1, 1991, p. 25-45; DIAS DE CARVALHO, A. Epistemologia das ciências da educação. Porto: Afrontamento, 1988; ESTRELA, A. C. Pedagogia ou ciência da educação? Revista Portuguesa de Pedagogia, Coimbra, ano 16, 1980, p. 125-31; ESTRELA, A. C.; FALCÃO, M. Para uma definição do estatuto epistemológico das ciências da educação. Revista Portuguesa de Pedagogia, Coimbra, ano 36, 1990, p. 367-72; MAZZOTTI, T. B. Estatuto de cientificidade da pedagogia. 16. ${ }^{a}$ Reunião da Anped. Caxambu, 12-17 set. 1993; MAZZOTTI, T. B. A Pedagogia como ciência da prática educativa. $7 .{ }^{\circ}$ Endipe. Goiânia, 5-9 jun. 1994; QUITANA CABANAS. Pedagogia, ciências de la educación. In: BARCALA, J. Basabe, et al. Estúdios sobre epistemologia y pedagogia. Madri: Amaya, 1983, p. 75-105; GOMEA, A. P. Ciências humanas y ciências de la educación. In: ESCOLANO, A. et al. Epistemologia y educación. Salamanca: Siguéme, 1978.
}

estudam a educação" (PIMENTA, 1988). Portanto, defende que, diferentemente das demais ciências humanas, que não colocam a priori, na investigação, a aplicação imediata do conhecimento, a pedagogia tem sua significação epistemológica assumindo-se como ciência da prática social da educação.

Da mesma forma, Franco (2003), ao defender a Pedagogia como ciência da educação, argumenta que

A pedagogia, para poder dar conta de seu papel social, deveria definir-se e exercer-se como uma ciência própria, que liberta dos grilhões de uma ciência clássica e da submissão às diretrizes epistemológicas de suas ciências auxiliares, a fim de que possa se assumir como uma ciência que não apenas pensa e teoriza as questões educativas, mas que organiza ações estruturais, que produzam novas condições de exercício pedagógico, compatíveis com a expectativa da emancipação humana. (FRANCO, 2003, p. 72).

Ao apresentar os fundamentos da pedagogia como ciência da educação, Franco é emblemática ao afirmar que "a base de formação dos profissionais da educação deverá ser os fundamentos dos estudos pedagógicos" (FRANCO, 2003), esclarecendo que, se inadequadamente se afirma que a base da identidade da formação do pedagogo é a docência, inverte-se a lógica dessa epistemologia, pois parte-se, para identificar um campo conceitual, de uma de suas decorrentes práticas, a docência, e não de sua matriz conceitual.

Libâneo promove um avanço na definição da Pedagogia como campo de conhecimento, como campo teórico e científico responsável pela problemática educacional, para o qual o objeto de estudo da pedagogia são as práticas educativas. Na sua compreensão,

[...] a pedagogia, antes de ser um curso, é um campo de conhecimento. Não se trata de insistir se ela é ou não uma ciência, mas que ela tem um corpo teórico, um conjunto de conceitos que, mesmo não sendo precisos e claros, formam uma base teórica para lidar com a prática educacional. Ou seja, o conhecimento pedagógico se define pelo campo empírico que é a realidade educativa, tem métodos de investigação que permitem a elaboração sistemática de resultados válidos, a explicação e compreensão dessa realidade para a transformação da prática [...] Então, eu defendo que a pedagogia é a teoria e a prática da educação, a pedagogia é o 
campo científico que faz uma reflexão sistemática sobre a prática educativa, a educação, que é o objeto de estudo da pedagogia. (LIBÂNEO, 2007, p. 16)

Dessa compreensão decorre que as práticas educativas, como objeto de estudo da pedagogia, são múltiplas na sociedade, e não restringem-se à escola e à docência, sendo uma delas a educação escolar. Por consequência, a docência é uma modalidade peculiar do trabalho pedagógico. Libâneo ressalta que esta deve ser a referência na formação do pedagogo escolar, mas que "o campo de atuação do profissional formado em pedagogia é tão vasto quanto são as práticas educativas".

Esses autores possibilitam avanços na definição do campo epistemológico da pedagogia, permitindo definir com mais clareza uma concepção e uma estrutura curricular de curso compatível com as necessidades de formação do pedagogo no interior das escolas e dos sistemas educacionais.

\section{Considerações Finais}

Como evidencia a citação de Gadotti (2001) que abre este artigo, mais de 30 anos de intensos debates sobre o curso de pedagogia e parece que a conclusão é sempre a mesma: precisamos avançar na definição da identidade do curso de pedagogia; precisamos chegar ao mínimo de consenso a respeito do caráter científico dessa área; precisamos construir respostas às críticas da inconsistência e fragmentação dessa formação; precisamos construir subsídios para formar o pedagogo com uma visão total do processo educativo, sem estar limitado à sua área de habilitação e/ou docência.

Repensar o curso de pedagogia e discutir suas Diretrizes Curriculares Nacionais do ponto de vista epistemológico se faz necessário e urgente, sob pena de reduzir o campo epistemológico da pedagogia, mais uma vez, ao centrar o percurso formativo na prática docente como pré-requisito para a formação do pedagogo, atribuindo apenas uma dimensão tecnológica de preparação técnica para o exercício do magistério para um curso que deveria fazer a mediação entre a relação teoria e prática.

\section{Referências}

ANFOPE. Documentos Finais dos IX Encontro da Associação Nacional pela Formação dos Profissionais da Educação. Brasília, 1998.

Documentos Finais dos $X$ Encontro da Associação Nacional pela Formação dos Profissionais da Educação. Brasília, 2000.

BRASIL. Ministério da Educação. Lei 9394, de 24 de dezembro de 1996. Estabelece as Diretrizes e Bases da Educação Nacional.

Resolução CP n ${ }^{0}$ 1, de 30 de setembro de 1999. Dispõe sobre os Institutos Superiores de Educação.

SESU. Parecer CNE/CP 009/2001.

Diretrizes Curriculares Nacionais para a Formação de Professores da Educação Básica, em nível superior, curso de licenciatura, de graduação plena. Brasília, 2001.

Conselho Nacional de Educação. Conselho

Pleno. Parecer CNE/CP 05/2005. Diretrizes Curriculares Nacionais para o Curso de Pedagogia Brasília: MEC/CNE, 2005.

Parecer CNE/CP

03/2006. Reexame do Parecer CNE/CP 05/2005, que trata das Diretrizes Curriculares Nacionais para o Curso de Pedagogia. Brasília: MEC/CNE, 2006.

Resolução CNE/CP

01/2005. Institui Diretrizes Curriculares Nacionais para o Curso de Graduação em Pedagogia. Brasília: MEC/CNE, 2006.

BRZEZINSKI, I. Pedagogia, pedagogos e formação de professores: busca e movimento. Campinas, São Paulo: Papirus, 1996.

COELHO, I. M. A questão política do trabalho pedagógico. In: BRANDÃO, C. R. O educador: vida e morte. Rio de Janeiro: Edições Graal, 1982.

CHAGAS, V. $\mathbf{O}$ ensino de $\mathbf{1}^{\mathbf{0}}$ e $\mathbf{2}^{\mathbf{0}}$ graus: antes, agora e depois. 2. ed. São Paulo: Saraiva, 1980.

FRANCO, M. A. S. Pedagogia como ciência da educação. São Paulo: Papirus, 2003.

GADOTTI, M. Educação e poder: introdução à Pedagogia do Conflito. São Paulo: Cortez, 2001.

KUENZER. A. Z. As políticas de formação: a constituição da identidade do professor sobrante. Revista Educação e Sociedade, ano XX, n.68, dezembro/1999.

LIBÂNEO, J. C.; PIMENTA, S. G. Formação de profissionais da educação: visão crítica e perspectiva de mudança. In: PIMENTA, S G. (Org.). Pedagogia e Pedagogos: caminhos e perspectivas. São Paulo: Cortez, 2002. 
Que destino os educadores darão a Pedagogia. In: PIMENTA, S. G. (Coord.). Pedagogia, Ciência da Educação? 2. ed. São Paulo: Cortez, 1998.

Educação, pedagogia e didática: o campo investigativo da pedagogia e da didática no Brasil: esboço histórico e busca de identidade epistemológica e profissional. In: PIMENTA, S. G. (Org.). Didática e formação de professores: percursos e perspectivas no Brasil e em Portugal. 2. ed. São Paulo: Cortez, 2000.

Pedagogia e pedagogos, para quê? 6.ed. São Paulo: Cortez, 2002.

. A pedagogia em questão. Entrevista com José Carlos Libâneo. Revista Olhar de Professor, Departamento de Métodos e Técnicas de Ensino, v. 10, n.1 Editora UEPG, 2007.

PIMENTA, S. G. A prática reflexiva no ofício de professor: profissionalização e razão pedagógica. Porto Alegre: Artmed Editora, 2002.

. (Coord.). Pedagogia, ciência da Educação? 2.ed.

São Paulo: Cortez, 1998.

. (Org.). Pedagogia e pedagogos: caminhos e perspectivas. São Paulo: Cortez, 2002.

RODRIGUES, M. F. Da racionalidade técnica à "nova" epistemologia da prática: a proposta de formação de professores e pedagogos nas políticas oficiais atuais. Tese de Doutorado. Programa de Pós-Graduação em Educação, Universidade Federal do Paraná, Curitiba, 2005.

; KUENZER, A. Z. As diretrizes curriculares para o curso de pedagogia: uma expressão da epistemologia da prática. Revista Olhar de Professor. Departamento de Métodos e Técnicas de Ensino, v.10, n.1, 2007.

Curso de Pedagogia ou Curso Normal Superior? Revista Brasileira de Política e Administração da Educação v.23, n.2, p.253-275, mai/ago, 2007.

SAVIANI, D. Transformações do capitalismo, do Mundo do trabalho e da educação. In: LOMBARDI, J. C., SAVIANI, D.; SANFELICE, J. L. (Orgs.). Capitalismo, trabalho e educação. Campinas, SP: Autores Associados, HISTEDBR, 2002.

SILVA, C. S. B. Curso de Pedagogia no Brasil: história e identidade. Campinas, São Paulo: Autores Associados, 1999.

Recebido para publicação: 25/04/2012

Aceito para publicação: 04/05/2012 